\section{IUMRS Lectureship Recipient Balkanski Presents Seminars and Lectures in Bulgaria}

Minko Balkanski, professor emeritus at the Université Pierre et Marie Curie in France and recipient of the 1995 IUMRS (International Union of Materials Research Societies) Lectureship, organized seminars and gave lectures in various materials research settings in Bulgaria. He had designed the mission of assisting Bulgarian cultural leaders, engineers, and scientists in the development of culture, science, and technology in their country.

At the university level, Balkanski organized a seminar in Sofia, Bulgaria on "Materials for Advanced Technologies," at which he gave three lectures on physics and applications of low-dimensional semiconductor structures. At the Bulgarian Academy of Science in Sofia, he lectured on intercalation-layered compounds. Balkanski visited the Technical University of Stara-Zagora to speak on materials for solid-state batteries and the Institute of Applied Physics in Plovdiv for a presentation on molecular beam deposition of layered materials with van der
Waals gaps. Graduate students and research workers from the university and academy laboratories attended the lectures and participated in the seminar.

To educate high school students on science, Balkanski visited the high school in Burgas where he talked informally with students about science in everyday life. $\mathrm{He}$ also talked with students at the high school in Sofia (Gymnasium of Mathematics) about new materials for renewable energies.

At NATO ASI (North Atlantic Treaty Organization Advanced Study Institute) in Sozopol, Balkanski presented two lectures on fabrication, properties, and applications of low-dimensional semiconductors. These lectures were published in the NATO ASI series High Technologies, volume 3, by Kluwer Academic Publishers. He also organized a NATO ASI in Sozopol on devices based on low-dimensional structures.

The IUMRS Lectureship is among the latest of honorific distinctions bestowed on Balkanski. He has previously received the Special Award for Distinguished Service to the Indian Institute of Technology in Delhi; the 1986 Von Hippel Award from the Materials Research Society (see MRS Bulletin, November/December 1986, p. 32); the Gold Medal of the University of Bologna and the Gold Medal of the Bulgarian Academy of Sciences; and the Doctor Honoris Causa of the Sofia University in 1992.

Balkanski is currently President of the Institut des Hautes Etudes pour le Developpement de la Culture, de la Science et de la Technologie en Bulgarie and director of the International School on Materials Science and Technology, Erice, Ettore Majorana Center for Scientific Culture in Sicily. He is a member of several editorial boards, editor of two publication series, and author or co-author of numerous publications.

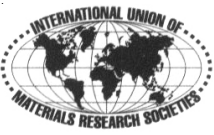

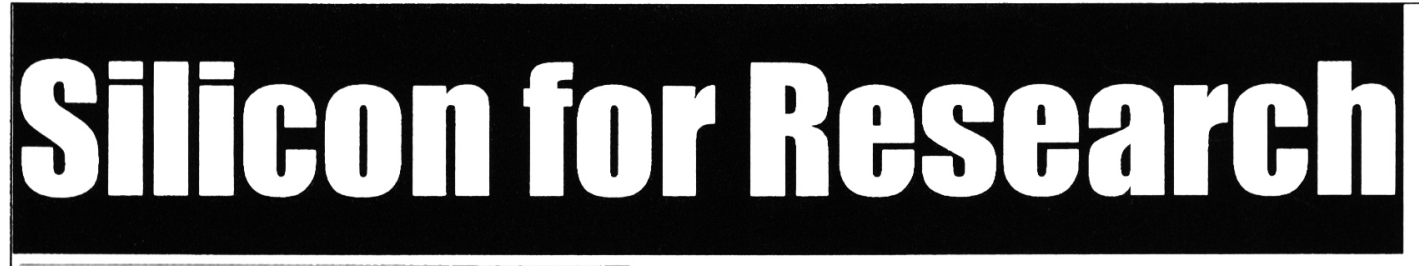

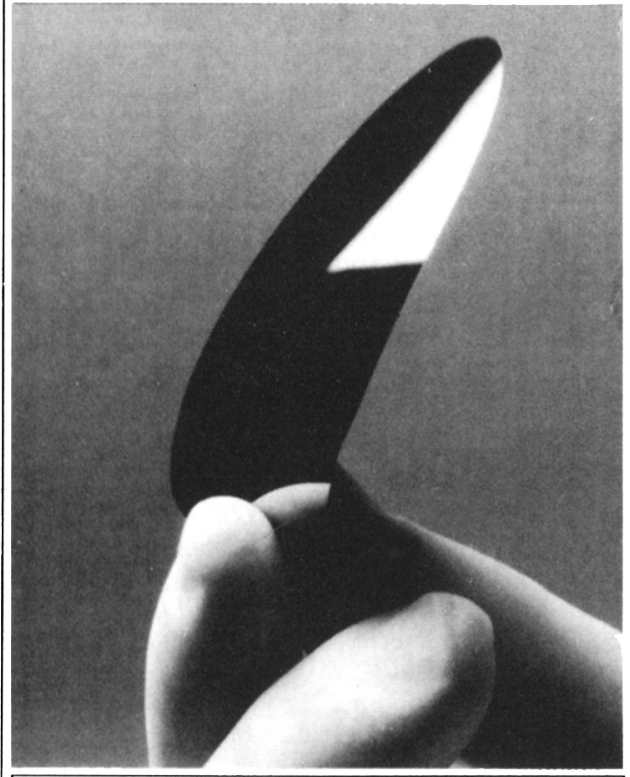

A 3" diameter 2-4 $\mu$ membrane manufactured at

VIrginia Semiconductor, Inc.
- think small quantities

- think thick or thin $(2-4 \mu)$
- think small diameter (1" to 4") your one source for all of the above. 1501 Powhatan Street, Fredericksburg, VA 22401 Phone (540) 373-2900 Fax (540) 371-0371

\section{When it comes to small diameter silicon requirements "If VSI can't make} them, you don't need them."

- think single or double side polishing

- think on or off axis for any orientation

- think Virginia Semiconductor, Inc.,

Circle No. 14 on Reader Service Card.

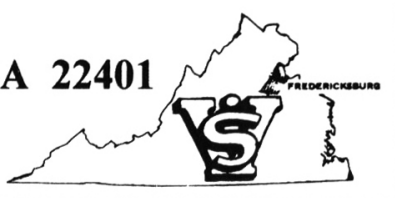

